\title{
La nación ecuatoriana
}

\section{The Ecuadorian Nation}

\section{René Maugé Mosquera}

Recepción: 28 de Agosto de 2015 Aceptación: 4 de septiembre de 2015

\section{Resumen}

El artículo es un breve resumen del discurso de incorporación del Dr. Maugé como académico de la Academia Nacional de Historia de Ecuador. Recupera la historia sobre la construcción de la nación ecuatoriana y resalta los elementos que definieron la construcción de la identidad nacional. Además avizora el futuro que le espera a las naciones latinoamericanas frente a un mundo nuevo y cambiante que exige la integración de las naciones para seguir existiendo.

Palabras clave: Ecuador, nación, identidad, colonialidad, génesis.

\begin{abstract}
The article is a brief summary of the speech of Dr. Maugé incorporation as academician of the National Academy of History of Ecuador. It traces the history of the construction of the Ecuadorian nation and highlights the elements that defined the construction of national identity. Furthermore envisions the future that awaits Latin American nations face a new and changing world that demands the integration of nations to continue to exist.
\end{abstract}

Keywords: Ecuador, nation, identity, colonialism, genesis. 


\section{Introducción}

n los tiempos que corren, existe un debate sobre la presunta obsolescencia y fin de las naciones, el fin de las ideologías, de la independencia y las soberanías nacionales. El trasfondo de este debate, y de muchos planteamientos, debe ser contextualizada en el proceso contemporáneo de un cambio de época, de la globalización como sistema mundo y de los planteamientos de la ideología neoconservadora, bautizada como neoliberal que pretende reducir a las sociedades y naciones a un mega mercado, a los ciudadanos y ciudadanas al rol de consumidores.

Como todos los vocablos políticos universales, el de "nación" tiene un contenido polisémico y flexible, que en el decurso del tiempo ha representado una realidad histórica relevante, multiforme y articulada. A más de la intencionalidad geopolítica de abolir las naciones, para facilitar la expansión de los mercados, y debido a la carga ideológica que se dio a la nación en el decurso de las primera y segunda guerras mundiales, la idea de "nación" no goza, en ciertos círculos, de buena reputación, sobre todo cuando a la comunidad histórica imaginada como nación, esto es, una forma particular de unidad que expresa un espacio simbólico dentro del cual se estructura una forma democrática, libre e independiente de relaciones sociales y políticas, se la confunde con ciertas expresiones de nacionalismo, que se dieron en Europa, en el período de entre guerras.

Existen discusiones y debates académicos importantes y no desestimables sobre la nación, sin embargo, hay que puntualizar que el acontecer histórico de las naciones y de los Estados no es académico sino político.

Otra premisa necesaria es evidenciar que una cosa son las ideologías del nacionalismo europeo y de potencias coloniales, que tantos perjuicios y tragedias han ocasionado a la humanidad, y otra cosa, es el esfuerzo de países que fueron colonias como Ecuador, por desarrollar una identidad, una personalidad en el concierto internacional para su- 
perar los rezagos de la dependencia colonial y de las nuevas formas de colonialidad del imperialismo sin colonias, que se expresan de diversas maneras, como: la colonialidad del poder, de la naturaleza, del ser y del saber. Es decir, de lo que se trata es de construir naciones y Estados independientes, libres y democráticos que superen toda forma de dependencia colonial o neocolonial.

El concepto y la realidad del Estado - nación, es una creación de la Europa moderna que sobre todo emerge en el proceso de la Revolución Francesa, cuando en un momento de la historia, la nación sustituye a las monarquías, ciudades y pueblos medievales, así como el vocablo ciudadano sustituye al de súbdito, o vasallo, siervo o esclavo. La nación, a partir de la Revolución Francesa, legitima al Estado que pasó a ser la expresión jurídico - política de la nación; y, que a su vez, es fortalecida por la idea democrática de que el poder emana de la nación, superando la idea del origen divino de los reyes o de los gobernantes.

Las naciones americanas actuales, como la ecuatoriana, emergen como resultado del proceso independentista y de la superación de su condición de colonia, y, si bien como han dicho quienes reflexionan sobre el fenómeno nacional, los grandes problemas actuales requieren soluciones multinacionales, transnacionales, continentales, incluso planetarias; de allí no se deriva el aplastamiento o eliminación de las naciones, sino nuevas formas de unidad respetando las individualidades, como el caso de la necesaria e impostergable unidad de las naciones de América Latina y el Caribe.

\section{Génesis de la nación ecuatoriana}

El proceso de poblamiento de lo que actualmente denominamos Ecuador se inició con las migraciones que desde Asia avanzaron al continente americano, por el estrecho de Bering hace unos treinta mil años. Así como también de otras migraciones provenientes de la Polinesia. Desde la presencia de los primeros pobladores en nuestro territorio, hace unos 
12000 años, se comenzaron a estructurar lentamente organizaciones primarias que los arqueólogos han denominado época aborigen.

Hacía el siglo V antes de Cristo, cuando en la Atenas de Pericles se inventó el concepto de democracia, el territorio actual del Ecuador

“contenía el mayor número de culturas diferentes por unidad de superficie en toda la región andina, pero no sólo un gran número de pueblos, sino conocemos que ellos habían desarrollado formas muy originales y más o menos equitativas de gestión de la diversidad, de manera que había una escasa conflictividad entre los diferentes: no se trataba de una multiculturalidad pasiva, ni conflictiva, todo lo contrario, activa, original y creadora” (Galo Ramón, 1985: 264).

España, potencia hegemónica en Europa en el siglo XV y XVI, pasó a ser también potencia hegemónica en las tierras descubiertas por Colón, medio siglo antes. La conquista y colonización fue un choque de civilizaciones. Para los españoles significó fama, riqueza y poder; pero, para los pueblos originarios de Abya - Yala fue una invasión que género desconcierto, destrucción, hundimiento de su civilización, reduciéndolos a la pobreza y a la miseria. Fue una colisión cósmica, telúrica, determinada por el curso de la historia en el que seguramente supuso como afirma la certeza para los aborígenes que sus dioses los habían abandonado, dada su profunda religiosidad (Watchel, 1981).

A la invasión sucede una catástrofe demográfica determinada por varias causas, la guerra, las enfermedades, las condiciones brutales de trabajo a las que fueron sometidos los nativos, así como factores subjetivos de incertidumbre, depresión, desaliento y sentimiento de derrota, abandono y humillación. Sobre estos últimos factores poco se ha reflexionado partiendo de los avances de la sicología moderna. 


\section{Periodo colonial}

Con la presencia y consolidación del régimen colonial español se creó un nuevo orden e institucionalidad jurídico - político, organizado en Virreynatos, Capitanías Generales, Reales Audiencias, Ciudades, Cabildos, Corregimientos y Gobernaciones, que representaban y eran expresión del Estado monárquico absolutista español que se encontraba en la fase superior de la Monarquía absoluta.

Más allá del nuevo ordenamiento jurídico - político, en el continente americano y en lo que hoy es Ecuador, tiene lugar un vasto y complejo proceso de mestizaje y aculturación, nuevas expresiones culturales, de usos y costumbres en medio de una complicada coexistencia que lentamente produce una fusión y síntesis. La Iglesia y la nueva religión venida de Europa llenó el vacío espiritual y les dio esperanza después de la vida a los oprimidos, de esta manera la nueva religión se convirtió en el suspiro de los pueblos agobiados por una hecatombe que seguramente no alcanzaron a comprender, pero esta nueva cosmovisión religiosa no la asumieron en su forma monoteísta pura Judeo - Cristiana, sino en la emergencia de un extraordinario sincretismo entre los dioses de sus ancestros y el nuevo Dios único y su corte celestial.

La conquista y colonización europea no fue sólo la imposición del más fuerte; sino, que desde la etnografía institucional, a partir de 1492, se institucionalizó la desigualdad mediante una estrategia para la explotación, imponiendo su imaginario de conceptos, para introducir la superioridad espańola y afirmar la inferioridad del "otro". La estrategia, como la formularon otras potencias coloniales, materializó la dicotomía superior - inferior, civilizado - primitivo o salvaje, naturalizando de esta manera el proyecto político - ideológico - epistémico que le facilitaba crear un orden económico, político, militar, moral y religioso, que implicó lo que podemos llamar la emergencia de la colonialidad del poder, del saber, del ser y de la naturaleza, que se prolonga hasta nuestros días, implementada bajo diferentes y sutiles modalidades. 
En la conquista de los andes septentrionales, donde hoy está ubicado el Ecuador, no sólo se dio un enfrentamiento entre españoles e indígenas, sino también, una guerra multilateral ente el Tahuantinsuyo y los pueblos sometidos a éste y los invasores europeos.

En el período colonial se produce otro fenómeno etnográfico; la presencia de población africana desde el siglo XVI en la Audiencia de Quito, como parte de la política colonizadora de Espańa para proveer de mano de obra esclava en la explotación de las minas de oro y plata, estos grupos humanos supieron adaptarse y mantener, al mismo tiempo, sus prácticas culturales e identidad étnica, diversificando el mestizaje.

Como primera conclusión, desde el punto de vista antropológico, podemos decir que en la formación de la actual nación ecuatoriana, confluyen tres grandes grupos humanos, los pueblos precolombinos parientes del tipo mongoloide con una antigüedad de 12 a 15000 años; los europeos de la península ibérica que acusaban ya un mestizaje por la presencia en la península ibérica de 700 años de musulmanes y distintas nacionalidades que, de manera casual, arribaron a un continente desconocido en 1492 y el contingente humano venido desde África. Ese es el origen y síntesis de nuestra identidad nacional que es parte de la aventura humana en el planeta tierra.

\section{Ruptura del sistema colonial, la independencia y la formación de las naciones latinoamericanas}

Como es conocido, el proceso independentista de todas las Américas, en particular de la América Hispana o Indoamericana y, dentro de ella, lo que es el Ecuador, tuvo causas internas y externas, se dio en el contexto internacional de las revoluciones burguesas, el hundimiento del régimen feudal y el surgimiento de las naciones modernas frente a la pujanza de una Inglaterra que, manteniendo la monarquía, avanzaba por el camino capitalista, dominando mares y mercados y una Francia que bajo las consignas emblemáticas de libertad, igualdad y fraternidad, 
abatía los pilares del feudalismo, la monarquía absoluta y su sistema epistemológico de valores. España se encontraba entumecida, inmóvil en lo económico y retrasada en lo espiritual bajo el dogmatismo de la inquisición.

Los tres siglos de dominio español, no fueron sólo de explotación, saqueo y crímenes, como la leyenda adversa a España lo expresa; sino que, según palabras del Libertador Simón Bolívar también fueron "tres siglos de cultura, ilustración y de industria" (Bolívar en Straka, 2007:25). En un análisis que hace el agente Francés Depons que estuvo en Caracas de 1800 a 1804 , dice sobre el sistema colonizador de España, que a diferencia de los sistemas seguidos por otras metrópolis "España formó en América verdaderas naciones con todos los elementos necesarios para su propia evolución” (Depons en Morón, 1986:55). Espańa como todo imperio fue al mismo tiempo opresor y portador de una nueva cultura, instituciones y costumbres.

Con la independencia, se produce otra ruptura, América Latina pierde la unidad político-administrativa, que aunque era insuficiente, formal y precaria, en definitiva era una unidad. En la década del 1820, el régimen colonial termina por fragmentarse en dos docenas de repúblicas independientes y divorciadas entre sí, a las que Simón Bolívar trató de darles unidad y coherencia.

En todo este proceso no puede desestimarse las influencias que vienen de otros procesos, en particular del euroatlántico del siglo XVIII, con los fenómenos que se dan en Gran Bretaña, Estados Unidos y Francia. Son influencias que actúan no sólo en el plano económico, sino también en el cultural, ideológico y político.

Los intereses del nuevo régimen capitalista, que se estaba gestando en América, exigieron imperiosamente que las colonias con su incipiente y subordinada organización se conviertan en Estados con un gobierno centralizado.

Siempre surge la pregunta ¿Por qué, mientras la revolución en las colonias británicas de Norteamérica unió a las 13 colonias en una nación, formándose un fuerte Estado nacional federal, la revolución de las co- 
lonias españolas llevó en cambio la desintegración del antiguo imperio colonial en un gran número de estados independientes?

Visión no faltó. Simón bolívar, con vigorosa claridad expresó el proyecto de integración nacional latinoamericana y la conciencia de sus dificultades "Yo deseo más que otro alguno ver formar en América la más grande nación del mundo, menos por su extensión y riqueza que por su libertad y gloria", "una sola debe ser la patria de todos los americanos ya que en todo hemos tenido una perfecta unidad", "Es una idea grandiosa pretender formar de todo el Mundo Nuevo una sola nación, con un solo vínculo que ligue sus partes entre sí y con el todo. Ya que tiene un origen, una lengua, unas costumbres y una religión, debería por consiguiente tener un solo gobierno que confederase los diferentes Estados" (Bolívar en Rojas, 1997:74).

El proceso de ruptura colonial del Ecuador no es tan simple como lo pintan algunos publicistas. La Real Audiencia de Quito, antecedente del Ecuador actual, tuvo dos etapas muy claramente marcadas, la primera de 1809 a 1812, en la que la iniciativa correspondió a las élites quiteńas, que propusieron un proyecto económico político concreto, expresión de sus intereses para restablecer la importancia de la Presidencia de Quito y establecer una Capitanía General que en 1804, habían solicitado al Rey de Espańa por medio del Barón de Carondelet. Tanto el manifiesto de la Junta Suprema de Quito a América, la proclama del 10 de agosto de 1809, así como la Constitución del Estado de Quito de 1812, contienen los elementos de la afirmación de una voluntad nacional. La segunda etapa del proceso independentista va de 1820 a 1822 , en la que adquieren mayor incidencia los proyectos continentales simbolizados por Simón Bolívar y José de San Martín.

Esta segunda etapa se inicia en Guayaquil el 9 de octubre de 1820, cuando las autoridades representantes de la corona española son destituidas y sus élites se pronunciaron por la libertad e independencia. La campaña libertadora culmina el 24 de mayo de 1822, con la victoria del Mariscal Antonio José de Sucre en las faldas del Pichincha.

El antiguo Reyno de Quito pasó a formar parte de la República de 
Colombia, creada por Simón Bolívar con el nombre de "Distrito del Sur", con desconocimiento de su personalidad histórica a pesar de que el propio Libertador Simón Bolívar, en la carta ya citada de Jamaica lo reconoce cuando dice "La Nueva Granada que es, por decirlo así el corazón de la América, obedece a un gobierno general, exceptuando el Reyno de Quito, que con la mayor dificultad contienen sus enemigos por ser fuertemente adicto a la causa de su patria" (Rivas, 2002:3). En esta segunda etapa de la lucha emancipadora, Guayaquil se incorpora a Colombia después del pronunciamiento del 9 de octubre de 1820 .

De 1824 a 1830, lo que fue la Real Audiencia de Quito, pasó a ser el Distrito Sur de Colombia, en la historiografía de nuestro país suele denominarse a este momento la Gran Colombia, denominación arbitraría, pues ni jurídica ni políticamente tal denominación existió en los documentos oficiales. Simón Bolívar, en 1826, reconoció oficialmente la personalidad de la nación Quiteńa o Ecuatoriana, dándole cierta autonomía. Cuando ingresamos a Colombia, estaba vigente desde 1821, la Constitución promulgada en Cúcuta. Para entonces las ambiciones e intereses y visiones diferentes de los principales actores de la guerra de la independencia, surgían como hongos asfixiando la posibilidad de una gran nación colombiana. La idea de la nación estaba clara, el artículo $1^{\circ}$ de dicha Constitución decía lo siguiente: "La nación colombiana es para siempre, e irrevocablemente libre e independiente de la monarquía espańola; y de cualquier otra potencia o dominación extranjera, y no es ni será nunca el patrimonio de ninguna familia o persona".

El artículo $2^{\circ}$ de la Constitución de Cúcuta señalaba que la soberanía reside esencialmente en la nación y el artículo 3 disponía: "Que es un deber de la nación proteger por leyes sólidas y equitativas la libertad, la seguridad, la propiedad y la igualdad de todos los colombianos.

En 1826, la convención de Ocańa convocada para tratar de superar las confrontaciones que ya eran patentes, fracasa y Simón Bolívar, contrariando sus sentimientos recurre a la dictadura no deseada, que duró hasta 1830. Se convocó el mismo ańo el Congreso constituyente, llamado Admirable, el cual elaboró la Constitución del 5 de mayo de 1830, 
que no alcanzó a tener vigencia sobre toda la espacialidad originaria de Colombia, puesto que Venezuela se separó en 1829 y se formalizó la creación del Estado de Venezuela en abril de 1830. La Constitución de Venezuela de 1830, recoge en el Título 1 de la Nación Venezolana y de su Territorio la misma formulación que hizo la Constitución Colombiana de Cúcuta, al proclamar en el artículo 1 que: "la Nación venezolana es la reunión de todos los venezolanos bajo un mismo pacto de asociación política para su común utilidad". La constitución Colombiana de 1830 que fue el preludio de la constitución ecuatoriana establece con absoluta claridad la voluntad de construir una nación, así: el artículo $1^{\circ}$ establece "La nación colombiana es la reunión de todos los colombianos bajo un mismo pacto político", el artículo $2^{\circ}$ reafirma que "La nación colombiana es indisolublemente libre e independiente de toda potencia o dominación extranjera, y no es ni será el patrimonio de ninguna familia o persona” y confirmando el artículo $3^{\circ}$ el criterio de que "La soberanía reside radicalmente en la nación. De ella emana los poderes políticos que no podrán ejercerse sino en los términos que establece esta constitución”.

El 13 de mayo de 1830, reunida por iniciativa del Procurador General del Ayuntamiento de Quito y previa venida del General Juan José Flores, Jefe Superior del Distrito Sur, se convocó a una Asamblea elitaria de la sociedad quiteña para deliberar "acerca de la situación de un cambio político" y resolvió en los siguientes términos: por cuanto "la mayoría de Colombia, pronunciándose por una nueva forma de gobierno ha disuelto la unión” y "no pudiendo Quito resistir por más tiempo a esta voluntad, ni mostrándose insensible a sus verdaderos intereses", en ejercicio de su soberanía, se pronuncia por constituir un Estado libre e independiente con los pueblos comprendidos en el Distrito Sur, y lo más que quieran incorporarse por las relaciones de naturaleza y recíproca conveniencia”, mientras se reúna la convención del sur, y se nombran los altos funcionarios, queda encargado del mando supremo civil y militar, el señor General de División Juan José Flores” quince días después de haber recibido las actas de los pueblos que deben formar con Quito 
un solo Estado, convocará el Congreso Constituyente conforme al reglamento de elecciones que expidiese al efecto"; y "si dentro de cuatro meses no se hubiere instalado la convención, se reunirá el pueblo para deliberar sobre sus destinos" (Acta de Quito, 1830).

Posteriormente, en días sucesivos esta voluntad de separación de las elites fue refrendada por los pronunciamientos de Guayaquil, Loja, Cuenca y las demás ciudades que formaron el nuevo Estado con el nombre de Ecuador, con el consentimiento pacífico de Colombia, la antigua Nueva Granada, que para entonces sufría desgarramientos y disensiones internas. En agosto de 1830, se instala la Primera Asamblea Constituyente del Ecuador, convocada por el General Juan José Flores. Con gran diligencia antes de los plazos de algunos pronunciamientos como el de Guayaquil que había dado seis meses plazo, se reunió en la ciudad de Riobamba y la Carta fue aprobada en la misma ciudad el 11 de septiembre de 1830. El mismo día 11, el General Flores, fue nombrado Presidente por unanimidad; esta unanimidad no se dio para elegir al vicepresidente, Dr. José Joaquín Olmedo, que en competencia con el General Manuel Matéu, logró dicha elección después de 18 escrutinios.

La Constitución de Riobamba dispone en su artículo 1 "Los departamentos de Azuay, Guayas y Quito quedan reunidos entre sí formando un solo cuerpo independiente, con el nombre de Estado del Ecuador". Artículo 2 "El Estado del Ecuador se une y confedera con los demás Estados de Colombia para formar una sola nación con el nombre de República de Colombia”. Artículo 6 "El territorio del Estado comprende los tres Departamentos del Ecuador en los límites del Antiguo Reino de Quito".

En cuanto a uno de los elementos fundamentales del Estado que es la territorialidad, base física del desenvolvimiento y sustento de las comunidades humanas, como también de la nación que contribuye a la afirmación de su existencia y personalidad, sus límites espaciales no estaban en discusión puesto que el principio que se estableció para la delimitación de las fronteras de las nuevas naciones, desde 1809 a partir 
de la proclamación de la independencia de las naciones americanas, fue el de "uti possidetis iuris", así como el Tratado de Guayaquil celebrado en febrero de 1830 que zanjó todo lo disputado con el Perú. Tampoco se varió ni el nombre ni el número de provincias, que eran Imbabura, Pichincha, Chimborazo, Cuenca, Loja, Guayas, Manabí, con la de Jaén y Mainas, cuyos confines meridionales no recibían aún su demarcación definitiva conforme al tratado del ańo anterior.

Fueron hechos posteriores que determinaron el recorte y una reducción sucesiva del espacio territorial nacional, que vio achicarse en estos años, hablando metafóricamente, como la "Piel de Onagro" de la novela de Balzac.

Como conclusión de este proceso cabe la pregunta ¿Qué tipo de Estado se constituye en 1830? La respuesta la dan Rafael Quintero y Erika Silva en su obra "Ecuador: Una nación en Ciernes", cuando afirman: "El Estado que se constituye desde 1830, antes que ser un órgano representativo de una clase legitimada por el consenso, se constituye en un organismo legitimador de los poderes terratenientes regionales. En ese sentido actuará como un sancionador legal de las medidas coercitivas y represivas puestas en práctica por los latifundistas en contra de los indígenas y pequeños campesinos" (Quintero \& Silva, 1998: 68).

\section{Cuestiones objetivas y subjetivas en torno a la identidad nacional}

Es común escuchar que los ecuatorianos no tenemos identidad nacional e incluso algunos publicitas sobre la base de un anecdotario, han escrito ensayos a este respecto. Pregunto: ¿Es verdad que los ecuatorianos carecemos de identidad nacional? Considero que una afirmación así de tajante no corresponde a la verdad, puede ser una verdad a medias $y$, como toda verdad a medias no contribuye al esclarecimiento $y$, lo que es más importante, no contribuye a forjar una sólida identidad que se fragua a través del tiempo, con una cultura y con una clara voluntad de forjar dicha identidad, por medio de objetivos claros, explícitos, perma- 
nentes y socializados por el conocimiento y dominio general de todos los ciudadanos.

El nacimiento del Estado nacional y la construcción de identidades nacionales en la época moderna a partir de la independencia fueron tareas claves para América Latina donde identidades indígenas y europeas habían sufrido una profunda transformación en los cincos siglos de cambio político, cultural y social. La tarea de construir una nación y su identidad, en la sociedad ecuatoriana es una tarea inacabada y mucho más compleja que en otras naciones latinoamericanas, debido a sus vicisitudes históricas.

América latina y consecuentemente el Ecuador se han desenvuelto entre dos tendencias simultáneas y diferentes: la implantación de estructuras feudales, semifeudales y esclavistas, por parte de los colonizadores españoles con su correspondiente carga ideológica, orden político, epistemológico e institucional; y luego, la irrupción del capitalismo y su ideología democrática liberal del naciente capitalismo Inglés y Francés. Más allá de los orígenes prehispánicos, las naciones y los nacionalismos latinoamericanos coinciden con la modernidad y el surgimiento de relaciones capitalistas y neocoloniales. Es por ello que en el proceso de construcción de la identidad nacional, este trasfondo, ha significado el nacimiento de formas y elementos híbridos que mantienen formas y expresiones conceptuales que sustentan lo señalado anteriormente, la colonialidad del poder, del saber, del ser y de la naturaleza.

Sabemos que el Ecuador es un país de contrastes, por lo tanto, sin conocer, entender y procesar esos contrastes no podemos entender ni construir una nación. Su ubicación ecuatorial y la presencia de su territorio en los Andes septentrionales, la Amazonía, el Océano Pacífico, configuran una original trama física y climática de la cual deriva una espectacular diversidad ecológica que se despliega en los 256370 kilómetros cuadrados que constituyen la superficie actual de la nación -Estado. Este acoge, además una sociedad pluriétnica y por esta misma razón rica en tradiciones culturales de todo orden de 16 millones 298 mil 625 habitantes. 
Consecuentemente partiendo de la geografía, de la historia, de las culturas y las características psicosomáticas de sus habitantes, podemos determinar algunos aspectos objetivos y subjetivos en torno a la identidad nacional. Es evidente que la historia de un pueblo está unida a un entorno de la naturaleza, por ello cuando adopta formas sociales y políticas no lo hace arbitrariamente, sino condicionando por su carácter, historia o geografía. No podemos hablar de identidad nacional si no partimos de supuestos físicos como el medio ambiente geográfico, el factor demográfico, los niveles de desarrollo económico, el factor de la ciencia y de la técnica, las instituciones y las culturas, entre otros.

La identidad es una consecuencia de la interactividad en los procesos que tienen lugar en la sociedad, de donde se deriva también de una u otra forma, el comportamiento individual que en última instancia es una respuesta a una situación determinada; interactividad que conforma lo que denominamos estructura social. Los asuntos de identidad nacional se encuentran enmarańados dentro de una gran complejidad emocional y lingüística.

Al momento de nuestra separación de Colombia en 1830, los larvados regionalismos afloraron, y por paradójico que parezca se impuso el nombre de una línea astronómica imaginaria, al nombre de Quito, que tenía una sólida raigambre histórica. El sueño y las urgencias de lograr una unidad que desde entonces tanta falta nos hace, para conformar una verdadera nación, y al parecer, en esos años turbulentos, más que formar una nación, se impuso el criterio de crear un Estado republicano. Tampoco es casual entonces que más se use el término país casi como sinónimo de nación y de Estado, para referirse a nuestra comunidad histórico - político, cuando el término "país" designa una realidad unitaria geográfica, pero no cultural.

Desde Aristóteles, Bodino y Montesquieu en su famosa obra, "el Espíritu de las Leyes" se ha reflexionado sobre la influencia del clima, la región, el comercio, la ocupación, la religión y las costumbres, en la conciencia y comportamiento de los hombres. El Ecuador es una nación marcada por claras diferencias regionales: costa, sierra, oriente o 
Amazonía e insular o Galápagos, lo que nos hace un país regionalizado y fragmentado, con diferentes intereses y donde las facciones dominantes de terratenientes y burgueses entre encuentros y desencuentros, se han disputado la hegemonía del poder, sin tener objetivos claros, peor un proyecto histórico que estructure sólidamente esa comunidad de destino, denominada nación.

Las diferentes regiones no deben ser un obstáculo para la unidad nacional, como muchos sostienen en el Ecuador, cuando levantan banderas de un enfermizo y falso regionalismo, basado en el desconocimiento, los prejuicios y el encono que es producto de la ignorancia. La región como bien expresa el geógrafo francés Paúl Vidal De LaBlanche: al decir "una región es una reserva de energía cuyo origen reside en la naturaleza, pero cuyo desarrollo depende del hombre. Es el hombre el que, moldeando la tierra según sus propósitos, produce su individualidad. Es él quien establece una conexión entre rasgos separados. El sustituye el efecto incoherente de las circunstancias locales por un concurso coherente de fuerzas" (LaBlanche en Presidencia de la Nación Argentina, s/a).

La identidad nacional, no es, en consecuencia algo que surge espontáneamente, sino que se forma a través de la conjunción de una serie de factores que determinan cierta originalidad o peculiaridad nacional. De estas premisas que originan el surgimiento y desarrollo de la nación, nace la autoconciencia nacional, cuyas raíces están en los intereses vitales de las personas, en la historia y el mito.

La identidad nacional no surge espontáneamente, se la forja cotidianamente en el sistema escolar, en las instituciones sociales de todo tipo, en los actos, en la exaltación de las fechas patrias de los héroes y personalidades y en los símbolos, está ligada a la conciencia social, que por supuesto no es homogénea sino que hay una conciencia social dominante de las clases dirigentes y otra consciencia social de las clases y grupos subalternos y explotados, que pugnan por sobrevivir en la adversidad. 


\section{El mundo de hoy y la nación}

El mundo actual no ha surgido de la noche a la mańana es el fruto de una larga evolución y particularmente estructurado bajo la arquitectura y principios que se dieron después de la Segunda Guerra Mundial al crearse las Naciones Unidas, sus organismos y sus políticas. En los actuales momentos existen una multidiversidad de factores positivos y negativos de todo tipo acumulados que han posibilitado el hecho de que entremos en un cambio de época, que para entenderla en su plenitud debemos comprender los avances generados por la revolución científico - técnica ya sea en el sentido de comprender los cambios positivos, cuantitativos y cualitativos, así como la generación de problemas globales que afectan a la humanidad en su conjunto. Teniendo en cuenta los nuevos escenarios continentales y mundiales, debemos reflexionar sobre el carácter de la nación ecuatoriana como una agrupación humana específica, entroncada con la naturaleza humana y que se ha formado y seguirá evolucionando con el ritmo de los grandes fenómenos históricos.

En el proceso de la construcción de una nación con colectividad plural y diversa como la ecuatoriana, se debe tener un programa para el presente y el futuro cuyos ejes fundamentales a mi juicio han sido definidos en la Constitución del 2008, sin perder de vista que la nación es un entramado de múltiples factores de extremada complejidad, que hay que comprenderlos, explicitarlos y desarrollarlos en una proyección geopolítica y geoeconómica que contenga por lo menos cuatro ejes:

1. Liberación de la dependencia;

2. Desarrollo integral del ser, esto es, del hombre y la mujer ecuatorianos;

3. Participación en la vida de la comunidad, esto es, participación democrática activa y responsable;

4. Protección de la naturaleza, fuente de la riqueza y base de la sobrevivencia. 
Siendo la nación ecuatoriana una y diversa, intercultural y plurinacional (en el sentido de la existencia de algunas nacionalidades y no en la coexistencia de varias naciones) su construcción permanente debe contemplarse como unidad e identidad en algunos aspectos y diversidad en otros; como continuidad de lo positivo y de afirmación de nuestro ser nacional; y ruptura para superar los desequilibrios e inequidades. Es necesario superar la estrechez de miras de ciertos grupos de poder dominantes, debemos lograr un equilibrio en función del reconocimiento y la práctica cotidiana de los derechos y deberes de ciudadanas y ciudadanos.

En la consolidación de los Estados - nación latinoamericanos, donde todavía pesa la herencia del pasado colonial y las nuevas formas imperialistas, en la inserción de la economía a los mercados mundiales a partir de la época de los imperialismos sin colonias, que es la realidad del capital moderno cuya expansión no requiere ya del sistema clásico de opresión nacional y de las actuales tendencias generadas por la globalización neoliberal y las convulsiones traumáticas que han aparecido por el cambio de época, las naciones latinoamericanas y entre ellas la ecuatoriana tenemos la impostergable tarea de superar las diversas estructuras adversas que persisten impidiendo desatar las fuerzas vitales de la nación.

La colonialidad del ser, del poder, del saber y de la naturaleza, han sido y siguen siendo factores de freno, y disgregación en la construcción de nuestras naciones, y pocos aspectos en la América Latina moderna, se pueden situar con tanta precisión en el legado colonial, como la desigualdad, sobre el trasfondo de la idea impuesta de raza, la dicotomía entre superior e inferior construcción mental que expresa la experiencia de todas las dominaciones coloniales ejercidas en diversos continentes. Su extensión bajo nuevas formas hasta nuestros días es evidente, si nos referimos a la colonialidad del poder como una estructura hegemónica global de poder y dominación que articula el superado concepto de razas que lleva implícita la superioridad de unos y la inferioridad de otros, en el trabajo, espacios y personas de acuerdo con las necesidades del 
capital y para beneficio de quienes se creen superiores. La colonialidad del ser es la dimensión ontológica que se afirma en la violencia y en la negación del otro.

Si entendemos que la historia de nuestra sociedad, del Estado y de la nación es una historia de construcción, fragmentación y reconstrucción, de coherencia y correspondencia, la construcción de la nación ecuatoriana y su correspondiente Estado, integrado por un complejo sistema de instituciones y de funciones de poder es una tarea inacabada, por lo que será una constante en el devenir del tiempo. En el proceso de la construcción de la nación ecuatoriana es significativo señalar el debate que se abrió a instancias mías en la Constituyente de 1998.

En una de las sesiones realizadas en la Universidad Andina, que hacía de sede de la Asamblea Constituyente a propósito del debate del artículo 1 que definió: "El Ecuador es un Estado Social de Derecho, Soberano, Unitario, Independiente, Democrático, Pluricultural y Multiétnico" sostuve la necesidad de definir al Ecuador en primer lugar como una nación para luego pasar a definir el carácter del Estado. Con esta oportunidad se dieron varias propuestas: una, que invocaba el espíritu milenarista con la aspiración utópica de reconstituir el Tahuantisuyo, sostenida por algunos representantes de nacionalidades ancestrales para quienes la nación blanco mestiza nunca los había integrado y peor representado; y la otra, proveniente de quienes fraguaban e impulsaban el proyecto "Singapur" de corte autonómico para la ciudad de Guayaquil. Estas dos tendencias convergieron para que no se defina al Ecuador como una nación. Para superar el impase, quién en ese momento presidia a la Asamblea Constituyente, planteó la formulación que consta en el preámbulo de dicha Constitución la misma que expresa: "La Asamblea nacional Constituyente expide la presente Constitución Política de la República del Ecuador. El pueblo del Ecuador inspirado en su historia milenaria, en el recuerdo de sus héroes y en el trabajo de hombres y mujeres que con su sacrifico forjaron, la patria; proclama su voluntad de consolidar la unidad de la nación ecuatoriana en el reconocimiento de la diversidad de sus regiones, pueblos, etnias y culturas”. 
Es indudable que esta redacción fue un compromiso entre dos posiciones que grafican cómo los grupos sociales y regionales en la perspectiva de sus intereses o sus frustraciones han antepuesto la afirmación de la nación ecuatoriana.

Como hemos señalado, el mundo en que vivimos en el primer cuarto del siglo XXI, es un mundo de mutaciones sin paralelo, de incertidumbres más que de certezas, donde está en juego no sólo la sobrevivencia de las naciones, como una creación humana sino que hay algo más profundo, está en juego la sobrevivencia de la propia humanidad y la civilización.

A diferencia de los albores de nuestra República, cuando Simón Bolívar convocaba a la unidad política de las naciones recién liberadas del coloniaje espańol, hoy en un mundo estructurado en mega bloques económicos que se disputan la hegemonía universal, forjar la unidad de América Latina y el Caribe, como un bloque de poder geopolítico y geoeconómico es un imperativo de sobrevivencia. Surge la pregunta: ¿unidad continental a secas o unidad de naciones interdependientes?

Un proceso de unidad en un continente en el que en los últimos 200 ańos se han fraguado naciones - Estados, es una colosal tarea que requiere ir definiendo objetivos, metas y programas. Es una tarea paciente, firme y constante que presupone romper esquemas, prejuicios y poderosos intereses. Se trata de organizar la vida y la democracia de 500 millones de personas. Será seguramente un sistema continental de organizaciones, una gran nación de naciones en la visión de Simón Bolívar, quién demandaba "hacer de toda América una sola nación"; o estructurar una confederación de Estados nacionales. La vida que es más rica que cualquier teorización irá abriendo caminos, lo importante en este transitar será la voluntad política de quienes gobiernen y sepan expresar los anhelos y necesidades de los pueblos por encima de los designios de las transnacionales, de los nuevos imperios financieros, del capital y de los proyectos de división y de fracturas de los enemigos de la unidad expresadas en sus visiones geopolíticas hegemónicas.

Una cosas es evidente: la necesidad histórica no es otra cosa que la 
expresión de las necesidades impostergables de los pueblos, y esa necesidad, por ser tal, se abrirá paso en medio de contradicciones y nuevas experiencias, como el caso de la UNASUR, la CELAC, y el ALBA, organismos en los que se crean nuevos espacios de integración y de defensa mutua como el proyecto de los presidentes de la región contra las intervenciones extranjeras, más allá de la ideología y de posiciones políticas. Está en curso la creación de espacios laicos de reflexión en América Latina y el Caribe, en materia de ciencia y tecnología; de defensa hemisférica y comercio, educación y cultura; y encuentros de comunidades y pueblos.

El ideal y la necesidad de integración continental no se opone a la existencia de nuestras naciones y Estados; todo lo contrario, se complementan en la medida que se entiendan y estudien los complejos problemas e intereses por los que están atravesadas las relaciones de los seres humanos, de los Estados, las naciones, las nacionalidades, los pueblos, las corporaciones e instituciones de todo orden. La unificación de nuestras naciones será la posibilidad para una más estrecha colaboración y acercamiento de intereses y perspectivas. Así como la formación del individuo en el goce de toda su plenitud de derechos y obligaciones, se integra con sus identidades y diferencias en la Constitución de una sociedad justa y solidaria; así mismo, la independencia y afirmación social y cultural de la nación es condición para una más estrecha colaboración y acercamiento entre nuestras naciones. Es la base para una libre vinculación, acercamiento y colaboración en todos los procesos de integración económica, política y cultural, características de la época actual, donde también los medios modernos de creación, intercambio y comunicación, como la radio, la televisión, el cine y el internet no reconocen fronteras nacionales.

La historia nacional no puede entendérsela aislada del continente americano ni de los procesos que, en el orden planetario, se dan actualmente. Somos el resultado de procesos contradictorios, de rupturas y continuidades como la conquista y la colonización, la independencia y la República. Y si hablamos de nuestro destino bien vale citar a William 
Jennings Bryan quien afirma: "El destino no es una cuestión de azar: es una cuestión de elección. No es una cosa que hay que esperar: es una cosa que hay que alcanzar” (Jennings en Martínez, 2013:25).

\section{Bibliografía}

Acta de Quito (1830). AFESE. http://www.afese.com/img/revistas/ revista54/actaquito.pdf

Constitución de la República del Ecuador (2008). Ecuador: Asamblea Nacional.

Martínez, H. (2013). Vivir con felicidad. Bogotá: Ecoe Ediciones.

Morón, Guillermo (1986). Historia general de América: Periodo colonial. Angloamérica II. Academia Nacional de la Historia de Venezuela. Venezuela: Universidad de Michigan.

Quintero, R. y Erika Silva (1998). Ecuador: Una nación en Ciernes. Ecuador: Flacso-Abya-Yala.

Ramón, Galo (1985). Revista Andina. Centro de Estudios Rurales Andinos "Bartolomé de las Casas". EEUU: Universidad de Michigan.

Rivas, E. (2002). Los condicionantes externos en los procesos de integración. Colombia: Editorial Froe.

Rojas, M. (1997). Los cien nombres de América. Colección identidad cultural. Costa Rica: Universidad de Costa Rica.

Straka, Tomás (2007). La voz de los vencidos. Venezuela: Editorial Latina.

Watchel, Nathan (1981). Suicidio, Holocausto y movimientos religiosos de redención en los Andes (SS. XV1-XVII). Revista Culture. N. 7-8, págs. 17-36. Roma: Bulzoni. 
Referencias electrónicas

Presidencia de la Nación Argentina (s/a). La geografía regional francesa: Paul Vidal de laBlanche. Disponible en: http://www.aportes.educ. $\mathrm{ar} /$ sitios/aportes/recurso/index?rec_id=107675\&nucleo=geografia_ nucleo_recorrido 